\title{
No adequate evidence indicating hypertension as an independent risk factor for COVID-19 severity
}

\author{
Gerui $\mathrm{Li}^{1} \cdot$ Hang $\mathrm{Li}^{1} \cdot$ Jinping $\mathrm{Lu}^{2}$
}

Received: 25 March 2020 / Accepted: 15 April 2020 / Published online: 23 April 2020

c) Springer-Verlag GmbH Germany, part of Springer Nature 2020

Sirs:

The meta-analysis of Li and colleagues entitled Prevalence and impact of cardiovascular metabolic diseases on COVID19 in China indicated that patients with hypertension are more likely to develop severe/ICU cases after 2019-nCoV infection. Hypertension accounted for $28.8 \%$ of ICU/severe cases, but $14.1 \%$ of non-ICU/severe cases. Moreover, the proportion of hypertension was about twofold higher in ICU/severe cases than in their non-ICU/severe counterparts (risk raio (RR) 2.03 (1.54-2.68), $p<0.00001$ ) [1]. However, these pooled results were obtained by analyzing data from only three studies, and moderate heterogeneity was shown $\left(I^{2}=41 \%\right)$. More importantly, none of the three included studies adjusted baseline confounding factors between ICU/ severe cases and non-ICU/severe cases, so a large number of confounders such as age and gender may seriously affect the effect size of this association. In more recent studies, Chen and colleagues [2] reported that critically ill patients were more likely to have coexisting hypertension compared to mild cases (35 (27.8\%) versus $14(58.3 \%), p=0.003)$. Univariate logistic regression analysis indicated that hypertension was significantly associated with the severity of COVID-19 (OR 3.64 (1.48-8.96), $p=0.005)$. However, statistical significance was not reached in multivariate logistic regression model (OR 2.59 (0.61-10.98), $p=0.198)$, i.e. comorbid hypertension was not an independent risk factor for the severity of COVID-19 in this study. A recent retrospective cohort study reported that coexisting hypertension was more commonly seen in patients with ARDS than in those without it (16 (13.7\%) versus $23(27.4 \%), p=0.02)$

Jinping Lu

lujp1024@163.com

1 Department of Cardiology, Zhongnan Hospital of Wuhan University, Wuhan 430071, Hubei, China

2 Department of Geratology, Zhongnan Hospital of Wuhan University, Wuhan 430071, Hubei, China
[3]. Bivariate Cox regression analysis showed that comorbid hypertension was significantly associated with higher incidence of ARDS (HR 1.82 (1.13-2.95), $p=0.005)$. However, this study did not adjust potential confounding factors, making the real magnitude of the independent association unknown. Therefore, the results from aforementioned studies need to be interpreted cautiously due to the potential bias and limited power. In brief, currently there is no direct evidence indicating comorbid hypertension as an independent risk factor for the severity of COVID-19. Further studies with an appropriate design and adequate power are required to robustly investigate this relationship.

It is suggested by Fang and colleagues that patients with hypertension who are often treated with RAS inhibitors may have an increased risk for COVID-19 infection [4], since treatment of RAS inhibitors was reported to increase the expression of ACE2, through which SARS-CoV-2 bind to the target cells [5]. On the other hand, previous study demonstrated that ACE2 expression is suppressed following SARS infection, inducing excessively activation of RAS and aggravation of pneumonia [6]. Thus, whether RAS inhibitors increase or decrease the risk for SARS-CoV-2 infection and disease progression has been a recent topic of intense debate. Fang et al. proposed that patients with COVID-19 should be monitored for ACEIs and ARBs, and anti-hypertensive calcium channel blockers could be a suitable alternative treatment [4]. Nevertheless, based on current evidences, we do not suggest arbitrary withdrawl or alteration of usual anti-hypertensive treatment, as complications induced by poorly controlled blood pressure might cause exacerbation of COVID-19 and even death. Indeed, the Council on Hypertension of European Society of Cardiology (ESC) also recommended that treatment with usual anti-hypertensive therapy should be continued, because there is no evidence suggesting the discontinuation of treatment with RAS inhibitors because of the COVID-19 infection [7].

Acknowledgements None. 
Author contributions GL and HL wrote the manuscript; JL conceived and revised the manuscript. All authors read and approved the final manuscript.

\section{Funding None.}

\section{Compliance with ethical standards}

Conflict of interest The authors declared there is no conflict of interest.

\section{References}

1. Li B, Yang J, Zhao F et al (2020) Prevalence and impact of cardiovascular metabolic diseases on COVID-19 in China. Clin Res Cardiol. https://doi.org/10.1007/s00392-020-01626-9

2. Chen C, Chen C, Yan JT et al (2020) Analysis of myocardial injury in patients with COVID-19 and association between concomitant cardiovascular diseases and severity of COVID-19. Zhonghua Xin Xue Guan Bing Za Zhi 48:E008-E008. https:// doi.org/10.3760/cma.j.cn112148-20200225-00123
3. Wu C, Chen X, Cai Y et al (2020) Risk factors associated with acute respiratory distress syndrome and death in patients with coronavirus disease 2019 pneumonia in Wuhan, China. JAMA Intern Med. https://doi.org/10.1001/jamainternmed.2020.0994

4. Fang L, Karakiulakis G, Roth M (2020) Are patients with hypertension and diabetes mellitus at increased risk for COVID-19 infection? Lancet Respir Med. https://doi.org/10.1016/S2213 $-2600(20) 30116-8$

5. Zhang H, Penninger JM, Li Y et al (2020) Angiotensin-converting enzyme 2 (ACE2) as a SARS-CoV-2 receptor: molecular mechanisms and potential therapeutic target. Intensiv Care Med. https ://doi.org/10.1007/s00134-020-05985-9

6. Kuba K, Imai Y, Rao S et al (2005) A crucial role of angiotensin converting enzyme 2 (ACE2) in SARS coronavirus-induced lung injury. Nat Med 11:875-879. https://doi.org/10.1038/nm1267

7. ESC Council on Hypertension (2020) Position statement of the ESC council on hypertension on ACE-inhibitors and angiotensin receptor blockers. https://www.escardio.org/Councils/Council-onHypertension-(CHT)/News/position-statement-of-the-esc-counc il-on-hypertension-on-ace-inhibitors-and-ang. Accessed $20 \mathrm{Mar}$ 2020 